\title{
The Development and Current Situation of mRNA Vaccines
}

\author{
Zilu $\mathrm{Qu}^{1, *}$ \\ ${ }^{1}$ School of Life Sciences, Henan University, Kaifeng, Henan Province, China, 475000 \\ *Corresponding author. Email:1557467827@qq.com
}

\begin{abstract}
In the past three decades, the use of RNA-based technology to develop preventive and therapeutic vaccines has attracted widespread attention and in-depth research.The proteins in our body coordinate with each other to perform their respective functions. And mRNA is like a set of procedures. Cells only need to process and synthesize proteins according to this set of procedures. The emergence of mRNA therapy is equivalent to using cells in the body as a factory for protein expression and transferring the expression process in vitro to the body, thus greatly shortening the development time. Moreover, by customizing the mRNA sequence, we can get any protein we want, allowing patients to produce their own therapeutic proteins, and promoting drug customization. There are two main types of mRNA vaccines currently in use, one is non-replicating mRNA(NRM) vaccines, and the other is self-amplifying (SAM) vaccines. This article summarizes the literature on mRNA vaccines published in the past 30 years, sorts out the development history of mRNA vaccines and the advanced technology of new crown vaccines, and reveals that mRNA vaccines have great research and development potential for rapid manufacturing and combating infectious diseases and other diseases.
\end{abstract}

Keywords: $m R N A$ vaccines, $m R N A$, SAM, LNP, COVID-19

\section{INTRODUCTION}

Since mRNA was first successfully extracted in 1960 to today, 60 years later, we have obtained the new crown mRNA vaccine by modifying the mRNA. The mRNA technology has great significance. It is also because of the sudden appearance of the coronavirus epidemic in 2019 that it gives the possibility of mRNA vaccines to be marketed in a short time, and promote the rapid development of the entire drug research field in the direction of mRNA therapy. It is known that scientists can skip the process of replication and transcription and directly translate them by introducing the mRNA containing the protein encoding the antigen into the human body to form the corresponding antigen to induce the body to produce a specific immune response, so as to achieve the effect of preventing immunity. Therefore, mRNA vaccines are expected to replace DNA vaccines. It not only retains the advantages of DNA vaccines, but also has no risk of integration into the host genome, and is generally considered safer than DNA vaccines. In addition, mRNA vaccines only need information about the nucleic acid sequence of the desired antigen, which is convenient to produce and can better respond to sudden infectious disease outbreaks. However, mRNA vaccines have not become mainstream for decades because they are limited by their instability and inability to spread in the body. Therefore, how to improve mRNA stability and translation efficiency, regulate immunogenicity, and develop efficient and non-toxic delivery vectors has also become the focus of subsequent mRNA vaccine research. Based on the prosperity and widespread application of mRNA vaccines, how mRNA vaccines enter people' $\mathrm{s}$ lives, how they act in the body, and their research potential have become the focus of attention. Therefore, the subject of this paper is the process of mRNA discovery and the results and future of mRNA vaccines in biology and oncology. This paper can give a detailed summary of the current stage of mRNA vaccine technology, the diseases treated by this technology, and also list the diseases that have not been prevented or resolved but are expected to be treated by mRNA vaccine technology. It is hoped that it can provide reference value for scientists to do further research, and also provide suggestions for future research and development directions. 


\section{THE REASON WHY MRNA HAS NOT BECOME MAINSTREAM}

\subsection{Limited by the conditions and technology at the time}

In the 1990s, because of the conditions at the time, it was difficult for scientists to conduct research on RNA. Because they can usually only isolate a small amount of RNA from the sample, and the RNA is easily degraded by RNase in the environment and physical contact. Since the 1990s, DNA genetic vaccines have emerged as an attractive immune method. The immune response it triggers is similar to that induced by live attenuated vaccines. However, due to the inherent characteristics of pDNA, this type of vaccine has potential safety hazards. And another option is to use mRNA for gene delivery and vaccination. In the same year, scientists directly injected reporter gene mRNA into mouse skeletal muscle to cause the expression of the encoded protein, and this was the first report on the successful application of IVT mRNA in animals. In 1991, mRNA was proposed as an active pharmaceutical ingredient for the treatment of cancer. Although it has been proven that it is feasible to deliver mRNA directly to mice, mRNA is mainly used for in vitro modification of antigen-presenting cells.

\subsection{Limited by mRNA own shortcomings}

However, these early promising results did not result in substantial investment in the development of mRNA therapies, mainly due to concerns about mRNA instability, high innate immunogenicity, and low delivery efficiency in vivo. Instead, the field is seeking treatments based on DNA and protein. Until 1995, scientists initially proved that mRNA stability can be improved through optimization and formulation. Since then, research on mRNA vaccines has exploded.

In 1997, the biggest problem encountered by scientists in the process of research was that both natural RNA and artificially synthesized in vitro RNA would activate the response of human immune cells, causing RNA to be degraded before it could be translated into protein. Until 2005, scientists discovered that when they modify uridine, one of the components of RNA, mRNA can evade the signal recognition of immunosensors, thus solving the previous problem. Since then, the field of RNA therapy has gradually attracted the attention of scientists in various fields.

\section{MRNA IS GAINING ATTENTION}

In 2007, some scientists conducted research on the application of RNA on stem cells based on the previous method of modifying mRNA uridine, trying to reprogram somatic cells into embryonic stem cells.
After more than a year of exploration, he found that the cell culture dishes under the microscope were full of embryonic stem cells they wanted to get after reprogramming. Three years later, scientists realized that this technology could be used in other fields besides reprogramming stem cells, such as drugs and vaccines. It can not only prevent diseases, but also treat many diseases, such as flu, tumors, cancer, etc., thereby saving thousands of lives. In this year, Noubar Afeyan co-founded Moderna with Derrick Rossi and Robert Langer. They have been committed to studying the mRNA encoding VEGF and so on. On the other hand, some scientists founded BioNTech, a biotechnology company based on mRNA therapy. In the following years, direct vaccination with mRNA molecules encoding tumor-associated antigens was considered a novel and promising method in tumor immunotherapy.

However, in order to achieve this technology and overcome its shortcomings, scientists have gone through decades of tireless exploration. In the second year, the complexation of mRNA required to overcome immune stimulation activities may inhibit its translatability.A two-component (containing free and protamine complexes mediated by Toll like receptor 7, TLR7) mRNA vaccine with duality (supporting both antigen expression and immune stimulation) was developed, then provided anti-tumor activity and transmitted anti-tumor information, which has laid the foundation for cancer vaccines.Since then, based on studies showing that two-component mRNA vaccines can induce very rapid and enhanced immune responses, scientists have proposed ways to adjust the vaccination schedule to suit the clinical situation, and combined chemical and other therapies and clinical data to demonstrate that the combination approach can induce a more effective antitumor response.In the same year, in order to improve the instability of mRNA vaccines, the high cost, and the limited production scale of mRNA transfected into dendritic cells in vitro, the scientists discovered virus-like particles (VLPs) based on MS2 produced in Saccharomyces cerevisiae[2]. With remarkable high stability, after constructing a mouse model, it proved that MS2VLPs can be used to design and construct a new and safe phage mRNA delivery vector. This finding was applied to the prevention and treatment of $\mathrm{PCa}[3]$ two years later. In addition, scientists have discovered that in situ electroporation (EP) can enhance the delivery and efficacy of self-amplified mRNA vaccines.

\section{MODIFICATION OF MRNA VACCINE}

Before 2015, we knew that the immune response was generated by naked mRNA, but their formulation with chemical carriers is expected to provide more specificity and internalization in DC to achieve better immune response and dose reduction. Therefore, in 
early 2015, scientists discussed the selective delivery of mRNALBF to promote intracellular accumulation in DCs[4] and reduce the effective dose. They also reported how to use $\mathrm{pH}$-sensitive lipids or polymers to achieve smart intracellular delivery to effectively escape mRNA from the endosome.This also lays the foundation for the next year to use LNP to deliver mRNA vaccines to prevent Zika virus, H7N9, H10N8 influenza virus, CMV, DENV, HIV and other infections, in order to induce a strong and well-tolerated protective cytotoxic $\mathrm{T}$ cell response .

In early 2016, scientists used SAM technology and characterized the immunogenicity and efficacy of self-amplified mRNA expressing influenza virus hemagglutinin antigen [SAM(HA)] formulated with a new type of oil-in-water cationic nanoemulsion[5]. Since then, the SAM vaccine has been applied to the prevention of H1N1 influenza, rabies, etc., supporting the concept of using SAM vaccine as a potential solution for a wide range of viral and bacterial pathogens.

In addition to meeting the needs of influenza prevention and anti-infective vaccinology, mRNA vaccines are also used for anti-tumor. Due to the development of sequencing technology and the variability of cancer in tumors, scientists have newly proposed a personalized mRNA vaccine that can determine patient-specific neoantigens by analyzing tumor exomes.

After 2017, based on the understanding and re-development of mRNA vaccines, various mRNA vaccines have been evaluated and applied in the clinic, such as preventive mRNA vaccines for anti-allergic use, mRNA vaccines enhanced by adjuvants, and use charge changes to release transporters for mRNA vaccination to trigger human $\mathrm{T}$ cell responses and cure tumors that have formed in mice, etc.The RNActive technology[6] is used to test its stability and its ability to induce sufficient immune stimulation.

In addition, in terms of mRNA vaccine delivery. It has been proven that mRNA vaccines are more stable, more effective and more specific than protein-based vaccines in stimulating humoral and cellular immune responses. In order to improve transgene expression in vivo, scientists have developed an injectable chitosan-alginate gel scaffold for local delivery of mRNA vaccines[7]. The transportation dynamics after delivery of mRNA vaccines can be observed through PET-CT and near-infrared imaging.

\section{THE OPPORTUNITY FOR THE DEVELOPMENT OF MRNA VACCINES IS COMING}

Shortly after the establishment of Moderna, the Bill and Melinda Gates Foundation invested in Moderna's
mRNA vaccine program to treat diseases caused by Zika virus and HIV. Pfizer and BioNTech have also collaborated to develop an mRNA influenza vaccine. However, the time for Moderna and BioNTech to shine is after the outbreak of the new crown epidemic. On the first day of 2020, the first article on COVID-19, "A COVID-19 mRNA vaccine encoding SARS-CoV-2 virus-like particles induces a strong antiviral-like immune response in mice"[8] was published. A week later, Chinese scientists announced the gene sequence of the new coronavirus, and both BioNTech and Moderna started the research and development of mRNA vaccines in the first place. The vaccine design of the two companies is to encapsulate the mRNA encoding the spike protein of the new coronavirus in liposomes. When the vaccine is injected into the body, the cells in the body can synthesize a large amount of viral protein through the mRNA and induce the immune system to recognize it. The protein thus generates an immune memory of the new coronavirus to resist viral infection.

This year, mRNA vaccines have achieved rapid development. In November, BioNTech's vaccine products BNT162 and Moderna successively applied for FDA emergency approval. According to the application documents submitted by Moderna, there are a total of 15,179 vaccine recipients and 15,163 placebo participants, and its effectiveness is more than $95 \%$. In December, two companies, BioNTech and Moderna, successively obtained emergency use rights for the new crown vaccine. On the 2nd, BNT162 was launched in the UK and is the world's first new crown vaccine.

In 2021, the epidemic will ease slightly but will continue, and vaccine development will continue. From the detectable antibody response to SARS-CoV-2 mRNA vaccine in saliva[9] to the clinical approval of SARS-CoV-2 mRNA vaccine based on nanotechnology[10]; from reports on the immunogenicity of COVID-19 mRNA vaccine in pregnant and lactating women[11] to the experience of SARS-CoV-2 BNT162b2 mRNA vaccine in dialysis patients[12]. To this day, it is the mRNA vaccine that we have universally vaccinated.

\section{DISCUSSION}

This paper also lists some examples of ongoing clinical trials of mRNA-based vaccines (Table 1). Based on my understanding of mRNA vaccines, I think that in the future, some cancers, rare diseases such as Alzheimer' s disease, frostbite, INAD, etc diseases can also be included in mRNA therapy. In addition, I think the traditional Chinese medicine theory is also very smart. In the future, the technology of mRNA vaccine can also be combined with the traditional Chinese medicine theory. Chinese and Western medicine cooperate with each other, from the inside out, from the 
root cause to the symptoms, so that patients can be better treated.

Table 1. Examples of ongoing clinical trials of mRNA-based vaccines[13]

\begin{tabular}{|c|c|c|c|c|c|c|}
\hline mRNA & $\begin{array}{l}\text { Mechanism of } \\
\text { Action }\end{array}$ & Disease/Condition & $\begin{array}{c}\text { Administration } \\
\text { Route }\end{array}$ & Study Phase & Sponsor/Collaborator & $\begin{array}{c}\text { National Clinical } \\
\text { Trial Identifier }\end{array}$ \\
\hline \multicolumn{7}{|l|}{$\begin{array}{c}\text { Therapeutic } \\
\text { mRNA }\end{array}$} \\
\hline W_ova1 vaccine & $\begin{array}{c}\text { Induction of an } \\
\text { anti-tumor immune } \\
\text { response }\end{array}$ & Ovarian cancer & Intravenous & Phase I & $\begin{array}{l}\text { University Medical Center } \\
\text { Groningen/BioNTech }\end{array}$ & NCT04163094 \\
\hline $\begin{array}{l}\text { CT7, MAGE-A3, and WT1 } \\
\text { mRNA-electroporated } \\
\text { Langerhans cells (LCs) }\end{array}$ & $\begin{array}{l}\text { Electroporation of } \\
\text { dendritic cells with } \\
\text { antigen mRNA }\end{array}$ & Multiple Myeloma & Subcutaneous & Phase I & $\begin{array}{l}\text { Memorial Sloan Kettering } \\
\text { Cancer Center }\end{array}$ & NCT01995708 \\
\hline $\begin{array}{c}\text { Personalized Cellular } \\
\text { mRNA }\end{array}$ & $\begin{array}{l}\text { Immunization with } \\
\text { DCs pulsed with } \\
\text { mRNA encoded } \\
\text { tumor antigens }\end{array}$ & $\begin{array}{c}\text { Brain } \\
\text { cancer/Neoplasm } \\
\text { Metastases }\end{array}$ & Not specified & Phase I & $\begin{array}{c}\text { Guangdong } 999 \text { Brain } \\
\text { Hospital/Beijing, Tricision, } \\
\text { Trinomab, Jinan University } \\
\text { Guangzhou }\end{array}$ & NCT02808416 \\
\hline Personalized mRNA & $\begin{array}{l}\text { Immunization with } \\
\text { DCs pulsed with } \\
\text { personalized mRNA }\end{array}$ & Glioblastoma & Not specified & Phase I & $\begin{array}{c}\text { Guangdong } 999 \text { Brain } \\
\text { Hospital/Beijing Tricision, } \\
\text { Trinomab, Jinan University } \\
\text { Guangzhou }\end{array}$ & NCT02808364 \\
\hline MiHA mRNA & $\begin{array}{l}\text { Immunization with } \\
\text { DCs loaded with } \\
\text { MiHA mRNA }\end{array}$ & $\begin{array}{c}\text { Hematological } \\
\text { malignancies }\end{array}$ & Intravenous & $\begin{array}{l}\text { Phase I } \\
\text { Phase II }\end{array}$ & $\begin{array}{c}\text { Radboud } \\
\text { University/ZonMw: } \\
\text { The Netherlands } \\
\text { Organization for Health } \\
\text { Research and Development } \\
\text { Dutch Cancer Society }\end{array}$ & NCT02528682 \\
\hline WT1-mRNA & $\begin{array}{l}\text { Immunization with } \\
\text { DCs electroporated } \\
\text { with WT1-mRNA }\end{array}$ & $\begin{array}{l}\text { Acute myeloid } \\
\text { leukemia }\end{array}$ & Not Specified & Phase II & $\begin{array}{l}\text { Zwi Berneman/Kom Op } \\
\text { Tegen Kanker } \\
\text { stichting tegen kanker } \\
\text { Research Foundation - } \\
\text { Flanders (FWO: Fonds } \\
\text { Wetenschappelijk } \\
\text { Onderzoek) }\end{array}$ & NCT01686334 \\
\hline
\end{tabular}

\section{CONCLUSION}

This article includes the history of mRNA vaccines and the current state-of-the-art technology. Every node in the past few decades has important significance. Although mRNA vaccines have encountered many problems along the way, through the tireless research of scientists, mRNA vaccines have made many improvements and improvements. Its combination with some adjuvants, biochemical physical technology methods, etc. has also expanded the application fields of mRNA vaccines. In the future, vaccines can be used not only to prevent infectious diseases, but also to prevent and treat cancer, and to eliminate allergens. Striving for mRNA vaccines can allow vaccine design and manufacturing to keep up with the pace of virus evolution.

\section{ACKNOWLEDGMENTS}

First of all, I really appreciate the professor who taught me during this time, Professor Cheng. The teaching assistant also explained in detail the questions I raised and the knowledge points I did not understand, which inspires me a lot. Secondly, I would like to express my sincere gratitude to my thesis supervisor. In the process of writing, she patiently helped me modify the format and sentences of the paper. Without her help, I could not complete a complete thesis.

\section{REFERENCES}

[1] Messenger RNA-based vaccines with dual activity induce balanced TLR-7 dependent adaptive immune responses and provide antitumor activity.
Fotin-Mleczek Mariola;Duchardt Katharina M;Lorenz Christina;Pfeiffer Regina;Ojki ć -Zrna Sanja Journal of immunotherapy (Hagerstown, Md.: 1997) 2011-01-21

[2] A new RNA vaccine platform based on MS2 virus-like particles produced in Saccharomyces cerevisiae. Sun Shipeng;Li Wenli;Sun Yu;Pan Yang;Li Jinming Biochemical and biophysical research communications 2011-04-01

[3] Messenger RNA vaccine based on recombinant MS2 virus-like particles against prostate cancer. Li Jinming;Sun Yanli;Jia Tingting;Zhang Rui;Zhang Kuo International journal of cancer 2014-04-01

[4] Lipid-based mRNA vaccine delivery systems Patrick Midoux; Chantal Pichon Expert Review of Vaccines 2015-02-01 Foreign Language Journals

[5] Induction of Broad-Based Immunity and Protective Efficacy by Self-amplifying mRNA Vaccines Encoding Influenza Virus Hemagglutinin. Brazzoli Michela; Magini Diletta; Bonci Alessandra; Buccato Scilla; Giovani Cinzia Journal of virology 2016-01-01 Foreign Language Journals

[6] RNActive ${ }^{\circledR}$ Technology: Generation and Testing of Stable and Immunogenic mRNA Vaccines. Rauch Susanne; Lutz Johannes; Kowalczyk Aleksandra; Schlake Thomas; Heidenreich Regina Methods in molecular biology (Clifton, N.J.) 2017-09-13 Foreign Language Journals

[7] Injectable Biodegradable Chitosan - Alginate 3D Porous Gel Scaffold for mRNA Vaccine Delivery Jingxuan Yan;Ruying Chen;Hong Zhang;James D. 
Bryers Macromolecular Bioscience 2019-02-21 Foreign Language Journals

[8] A COVID-19 mRNA vaccine encoding SARS-CoV-2 virus-like particles induces a strong anti-virus-like immune response in mice Jing $\mathrm{Lu}$; Guoliang Lu; Shudan Tan; Jia Xia; Hualong Xiong Cell Research 2020-01-0

[9] Antibody response to SARS-CoV-2 mRNA vaccine can be detected in saliva. Ketas Thomas J;Chaturbhuj Devidas;Portillo Victor M Cruz;Francomano Erik;Golden Encouse Pathogens and Immunity 2021-01-01 Foreign Language Journals

[10] Clinical approval of a nanotechnology-based SARS-CoV-2 mRNA vaccine: implications for translational nanomedicine. Milane Lara; Amiji Mansoor Drug Delivery and Translation Research 2021-01-29 Foreign Language Journals

[11] Immunogenicity of COVID-19 mRNA vaccine in pregnant and lactating women. Collier AiRis Y;McMahan Katherine;Yu Jingyou;Tostanoski Lisa H;Aguayo Ricardo JAMA 2021-05-13 Foreign Language Periodicals

[12] Experience of using SARS-CoV-2 BNT162b2 mRNA vaccine in dialysis patients Yanay Noa Berar; Freiman Sarit; Shapira Ma'anit; Wishahi Samar; Hamze Munir Kidney International 2021-05-21 Foreign Language Journals

[13] Opportunities and Challenges in the Delivery of mRNA-Based Vaccines Abishek Wadhwa; Anas Aljabbari; Abhijeet Lokras; Camilla Foged and Aneesh Thakur Department of Pharmacy, Faculty of Health and Medical Sciences, University of Copenhagen, Universitetsparken 2, DK-2100 2020-01-28 